\title{
Improved ecological monitoring for urban ecosystem protection in China
}

\author{
Min Wang ${ }^{\mathrm{a}}$, Bo Jiang ${ }^{\mathrm{b}}$, Juha M. Alatalo ${ }^{\mathrm{c}, \mathrm{d}}$, Yang Bai ${ }^{\mathrm{e}, \mathrm{f}, *}$, Qing Wang ${ }^{\mathrm{a}}$, Juan Tan ${ }^{\mathrm{a}}$, Junjie Ruan ${ }^{\mathrm{a}}$, \\ Jinghua $\mathrm{Su}^{\mathrm{a}}$

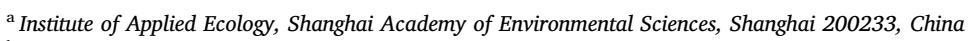 \\ ${ }^{\mathrm{b}}$ Changiiang Water Resources Protection Institute, Wuhan 430051, China \\ ${ }^{\mathrm{c}}$ Department of Biological and Environmental Sciences, College of Arts and Sciences, Qatar University, P.O.Box: 2713, Doha, Qatar \\ ${ }^{\mathrm{d}}$ Environmental Science Center, Qatar University, P.O.Box: 2713, Doha, Qatar \\ ${ }^{\mathrm{e}}$ Center for Integrative Conservation, Xishuangbanna Tropical Botanical Garden, Chinese Academy of Sciences, Xishuangbanna 666303, China \\ ${ }^{\mathrm{f}}$ Center of Conservation Biology, Core Botanical Gardens, Chinese Academy of Sciences, Mengla 666303, China
}

\section{A R T I C L E I N F O}

\section{Keywords:}

Ecological monitoring

Science-policy framework

Standards

Shanghai

Metropolitan parks

\begin{abstract}
A B S T R A C T
Ecological monitoring (EM) is a significant scientific topic recognized for its potential for providing basic, but vital, data for ecosystem assessment to address sustainability issues. However, a monitoring framework that can lead to EM information and data being used accurately in ecosystem management and policy design is currently lacking. China's Ecological Redline Policy (ERP), one of the first national policies utilizing multiple ecosystem service assessment, requires strict monitoring to reveal policy effects on ecosystem services regulation. In this study, we developed a transdisciplinary framework to build up the ecological redline monitoring network in Shanghai metropolitan area, using: biodiversity, landscape structure, ecosystem function, and stakeholder opinions. We suggest that standard monitoring be based on remote sensing monitoring, supplemented by ground truth monitoring, to form a standard 'Space-Sky-Ground' integrated monitoring network. We also present key lessons learnt from EM practices in Shanghai. This work provides new insights on integrating EM into ERP implementation and ecosystem management on city scale, by illustrating the science-policy process and ER monitoring standards from initial design to application in policy.
\end{abstract}

\section{Background}

Ecosystem protection is generally considered a national priority, as ecosystems are capable of providing various ecological goods and services that are important for human beings (de Groot et al., 2010; Bai et al., 2018). Key national ecosystem protection strategies (e.g., nature reserves, national parks, etc.) have been implemented in the United States, United Kingdom, Canada, Mexico, France, China, and many other countries world-wide (Shelford, 1941; Abella et al., 2015; Kavaliauskas and Nurijeva, 2015). In order to transform the development approach from 'grow first, clean up later' to 'ecological civilization', China has unprecedentedly issued a new national policy called Ecological Redline Policy (ERP) (Bai et al., 2016; Jiang et al., 2019). The term 'ecological civilization' in China refers to a political vision for managing the relationship between human and nature in a harmonious, scientific, and systematic manner (United Nations Environment Programme, 2016). In 2013, Chinese president Xi set up a new target to delineate and defend ERP. ERP was then integrated into Chinese environmental protection law and a temporary technical document was released in 2014 by the Chinese Ministry of Environmental Protection (CMEP) (CMEP, 2014; Fan et al., 2018). Technical methods for delineating ecological redline were initially formulated (Yao et al., 2019). The standard technical document, providing more details and explaining technical procedures for identification of ecological redline, was released in 2015. It emphasized the importance of protecting the integrity of important ecosystems in order to meet stakeholder needs for diverse ecosystem services (CMEP, 2015; Bai et al., 2016). In general, three types of hotspots should be identified: eco-function hotspots, eco-fragile hotspots, and biodiversity hotspots.

ERP seeks to mandate governments at all levels to use the minimum ecological area to sustain critical ecosystem services (ESs) for social welfare, using coordinated land use planning. All municipalities and provinces must designate ecological redline areas (ERAs) and must evaluate the effects of ERP in optimizing land use planning. ERAs represent an attempt at establishing ESs assessment in land use planning, where an ERA is defined as the "minimum ecological area needed to

\footnotetext{
* Corresponding author at: Center for Integrative Conservation, Xishuangbanna Tropical Botanical Garden, Chinese Academy of Sciences, Xishuangbanna 666303, China.

E-mail address: youngbcs@gmail.com (Y. Bai).
} 
guarantee and maintain ecological safety and functionality, and biological diversity for national security" (Bai et al., 2016). Consequently, there is an urgent need to evaluate the effects of ERP, in order to inform land planning optimization.

Ecological monitoring (EM) offers a means of gathering information for comprehensive and accurate ecosystem assessments within integrated approaches to reveal the effects of ERP (Park and Hwang, 2016). There is currently a problem with lack of standardized monitoring data, which could impact the credibility and usability of evaluations of the effects of ERP. Various monitoring stations have been established throughout China for different purposes (e.g., monitoring soil erosion or carbon flux) and for different stakeholders (e.g., state, institutional, private) (Nielsen et al., 2009; Li et al., 2015). A major challenge is developing monitoring capacity to supply data for ecosystem assessments, due to a lack of EM standards (on e.g., monitoring protocols, targets, objects, and periods). Accurate monitoring data are essential for comprehensively and effectively revealing complex environmental conditions and social concerns (Manley et al., 2005; Longman et al., 2018). Despite increasing political and scientific interest in EM, the amount of EM information available for assessments remains quite limited.

Scientific monitoring networks at various levels would enable progress in gathering ecological data and information for ESs evaluation and assessment (Buckland et al., 2005; Haase et al., 2014). However, there is a fundamental lack of monitoring frameworks applying EM standards for policy evaluation and management optimization. Therefore, in this study we developed a monitoring framework that builds upon stakeholder concerns and core ecological components for ERP evaluation and ERAs optimization. When applying this transdisciplinary framework and core elements of EM for ERP, we propose four main indicators to standardize the effectiveness of ERP evaluation processes: (i) biodiversity inventory (i.e., species numbers and distribution), (ii) landscape structure (i.e., composition and configuration), (iii) ecosystem function (i.e., biomass, net primary productivity, and vegetation coverage), and (iv) stakeholder opinions.

Shanghai is a priority ERP region and has made great efforts in monitoring ERAs for ERP evaluation (Bai et al., 2018). Shanghai is a mega-city and one of the most urbanized cities in China. The contradiction between rapid development of the social economy and a continuous shortage of ecological resources is prominent in Shanghai, as in many other global mega-cities. The overriding characteristic of Shanghai's ERP is to fully coordinate the relationship between urban ecological protection, urban economic development, and human needs (Bai et al., 2018).

Shanghai's efforts and experience in ERAs monitoring and supervision can act as important reference for other municipalities in China and other international cities. Here, we used its experiences of ERAs monitoring to inform the governance process for evaluating the effectiveness of China's ERP. Specific objectives of the study were to: (1) Identify standards of EM indicators and methods for evaluating the effectiveness of ERP in Shanghai municipality; and (2) develop a comprehensive but easy-to-use EM framework for gathering necessary information for ERP evaluation.

\section{Current status in ERAs demarcation and monitoring in China}

Since China officially formulated a "national redline for ecological protection", governments at all levels across the country have begun to establish ERAs (Xu et al., 2015; Bai et al., 2016). Due to differences in resources, conditions, and economic development, progress in demarcating ERAs differs between provinces and cities. According to official data, around $48 \%$ of the provincial administrative units in China had completed their ERAs demarcation by the end of 2017, and these ERAs were approved by the State Council and became permanent local policy in 2018 . The remaining $52 \%$ of provincial administrative units have formulated preliminary plans for demarcating ERAs and have submitted these to the State Council for approval (Jiang et al., 2019). The overall goal is to complete demarcation of the ERAs for national ecological protection by the end of 2020 , at which point the protection target of $25 \%$ of the country's land area will be achieved (The State Council, The People's Republic of China, 2017).

An effective monitoring system and platform is of particular importance to ensure that ERAs are demarcated firmly, consistently, and sustainably. However, progress on EM for ERAs is currently very slow, due to lack of monitoring standards and limited budgets. China's National Development and Reform Commission has approved construction and completion of a national ERAs monitoring platform by the end of 2020, with a total investment of RMB 286 million (Peng, 2018). A major challenge is developing capacity for gathering the monitoring information necessary to effectively reveal complex ecological components and stakeholder concerns.

\section{Shanghai's practice}

Shanghai was one of the first priority regions in China to establish ERAs, which were approved by the State Council in 2018. According to the official announcement by Shanghai Municipal People's Government (SMPG), ERAs in Shanghai municipality cover a total area of $2,082.69 \mathrm{~km}^{2}$ and contain a wide range of important ecological spaces, such as vital areas for biodiversity conservation and for water conservation, islands under special protection, important coastal wetlands, and natural shorelines (SMPG, 2018).

In order to ensure implementation of ERP and the effectiveness of its performance evaluation, Shanghai municipality has been the first of all China's provinces and municipalities to attempt to build a local ERAs monitoring platform. Shanghai Municipal Bureau of Ecology and Environment has hosted several rounds of negotiation on designing the ERAs monitoring program and scheme. Government departments with relevant administrative functions and scientists from universities and research institutes were tasked with establishing this scheme, which mainly involves remote sensing monitoring and ground truth monitoring. Landowners were then summoned to discuss the feasibility of the system and compensation for construction of ground truth monitoring stations. Finally, all stakeholders reached agreement and the ERAs monitoring scheme was established, with Haiwan national forest park being selected as the first site for construction of a ground truth monitoring station. The reasons why Haiwan national forest park was selected were as follows: (1) It is the largest urban forest ecosystem in Shanghai and also the largest ERA patch (covering an area of $11.45 \mathrm{~km}^{2}$ ); (2) it has a complete three-dimensional ecosystem (i.e., tree, shrub, and herb layers) and many local species (e.g., Sapium sebiferum, Camptotheca acuminate, Bischofia polycarpa and Cinnamomum camphora); and (3) it is easily accessible and has an electricity supply. These characteristics can also be used as criteria for site selection in other provinces and municipalities in China.

The Haiwan station covers a total area of $100 \mathrm{~m}^{2}(10 \mathrm{~m} \times 10 \mathrm{~m})$ and the main body is a regular quadrilateral steel structure tower $(2 \mathrm{~m} \times 2 \mathrm{~m})$ that is $25 \mathrm{~m}$ high. Extension rods are fitted at different heights on the tower for installation of various monitoring instruments. The Haiwan ERAs monitoring scheme covers five ESs (biodiversity maintenance, carbon sequestration, urban heat island mitigation, water supply, and water purification) demanded by the beneficiaries. These were agreed during the negotiation process and reflect stakeholder concerns and benefits at various spatio-temporal scales. Overall, the Haiwan station automatically monitors more than ten indicators, which cover various material fluxes, including water, gas, and heat fluxes (Table 1), and can also be used for ERP effectiveness evaluation.

The original data for biodiversity are mainly collected in annual field surveys. The original data for landscape structure and ecosystem function indicators are mainly collected by drone, and further analyzed in the laboratory. The results for these indicators are verified using field survey data. The original data for material flux indicators are mainly 
Table 1

Ecological monitoring indicators and standards used to evaluate ecological redline areas (ERAs) in Haiwan national forest park, Shanghai, China.

\begin{tabular}{|c|c|c|c|}
\hline Targets & Indicators & Method & Frequency \\
\hline Biodiversity & Species number; species composition; communities & Ground truth monitoring & Every year \\
\hline Landscape structure & Area; percentage; fragmentation; connectivity & Remote sensing monitoring & Every year \\
\hline Ecosystem function & Biomass; net primary production; vegetation cover index & $\begin{array}{l}\text { Ground truth monitoring and remote } \\
\text { sensing monitoring }\end{array}$ & Every year \\
\hline Material flux & $\begin{array}{l}\text { Air temperature and humidity; rainfall; carbon dioxide flux; sensible heat flux; stem } \\
\text { flow; dissolved oxygen and } \mathrm{pH} \text { for water }\end{array}$ & Ground truth monitoring & Every day/online \\
\hline
\end{tabular}

collected from various sensors installed on the monitoring tower. Each sensor automatically records and automatically transmits data wirelessly via a cellular network to a server on the office computer for further use. Tables S1 and S2 in Supplementary Information provide details about the frequency, sensitivity, resolution, and type of sensors using in monitoring material flux indicators.

An open, continuous EM platform that allows automatic updating in real time is under construction. The proposed architecture of this platform is technically divided into seven levels, namely data acquisition layer, data processing layer, status monitoring layer, evaluation layer, diagnostic layer, decision support layer, and layout layer. Each layer remains relatively independent and can be open to separate interactions with other systems.

\section{Lessons learnt and EM framework}

The main lessons learnt from Shanghai's first ERAs monitoring station concern the need for: (1) comprehensiveness: ecosystem composition, processes, and functions should be monitored as fully as possible; (2) continuity: the selected indicators should be measurable continuously over a long time span; (3) standardization: selection of metrics and of height/depth measurements should be as consistent as possible with those at other sites, so that data can be compared; and (4) negotiation: ERAs monitoring involves various stakeholders, and it is important to negotiate with all stakeholders and involve them in EM (Shoyama et al., 2017).

Based on the characteristics of the ERA itself, such as wide range, large area, and ecosystem types, and integrating the lessons learnt from Shanghai's practice, standard monitoring of ERAs should be based on remote sensing monitoring, supplemented with ground truth monitoring, to create a standard 'Space-Sky-Ground' integrated monitoring network (Fig. 1). Using this network, scientists can obtain monitoring data on ERAs, grasp the composition, distribution, and dynamics of the ecosystems in ERAs, perform timely evaluations and issue pre-alerts for ecological risks, monitor human interference activities, and identify behaviors that damage ERAs.

Each of the indicators in the network (Table 1) is useful and corresponds to a specific desired ecological redline benefit, such as biodiversity maintenance, climate regulation, and greenhouse gas reduction. By evaluating the performance of ERAs, policy makers can obtain information on how to best manage ERAs and optimize ERP (Fig. 1).

\section{Future applications and conclusions}

China currently has a unique decision-making context, since the central government wants ecosystem service information so that all provinces and cities can select suitable ERAs for national protection (Bai et al., 2018; Jiang et al., 2019). Having successfully demarcated ERAs, the Chinese government faces the problem of how to effectively monitor these ERAs. The government needs ecosystem services information from scientists to devise better actions, while scientists in turn need accurate monitoring data to comprehensively evaluate changes and benefits to ecosystem services. The lack of an EM framework and standards for policy has led to confusion and inconsistency across China. Many EM stations have been set up in China, but few have led to local policy changes.

The present work provides new insights on integrating EM into ERP implementation and ecosystem management by describing an EM framework from initial design to application in policy. There is currently a lack of science-based examples of EM application as part of ERP. In a case study, we devised a way to incorporate the needs of stakeholders into the development of EM in practice in Shanghai.

Based on our experiences and the latest 'Technical regulation for monitoring ecological conservation redline (exposure draft)' issued by the Ministry of Ecology and Environment of the People's Republic of China, we identified seven key lessons and used these to formulate the following suggestions on the science-policy process for EM. First, a unified national EM platform should be established to collect monitoring data from all parts of the country, for data integration and networked observation. Second, work on setting up a monitoring station should combine the needs of government and stakeholders, so that monitoring, scientific research, and policy making can be effectively integrated. Third, standardization of monitoring stations should be carried out, so that the data from different stations can be effectively integrated and compared. Fourth, the selection of monitoring indicators should reflect the integrated state of the ecosystem in ERAs. Indicators for ecosystem size, structure, and function should be included. Fifth, the needs of stakeholders should be considered and monitoring data used effectively to evaluate potential benefits to guide policy making. Sixth, funding for EM and the number of sites for EM station construction should be increased, and more basic monitoring data on national and global scale should be obtained to guide policy making. Seventh, the monitoring stations built should be used as places for scientific research and education, so as to increase public participation and publicity.

In conclusion, our study supports the use of EM information in landscape planning for developing more comprehensive plans for ecosystem protection. Moreover, we present a new framework and standards for ER monitoring that is designed to work in continuous mode, and has the features of openness and ability to work in real time. We hope it can advance domestic efforts in China and similar efforts internationally.

\section{CRediT authorship contribution statement}

Min Wang: Data curation, Formal analysis, Writing - original draft, Writing - review \& editing. Bo Jiang: Conceptualization, Methodology, Writing - original draft. Juha M. Alatalo: Writing - original draft, Writing - review \& editing. Yang Bai: Conceptualization, Funding acquisition, Supervision, Validation, Writing - original draft, Writing review \& editing. Qing Wang: Writing - original draft. Juan Tan: Writing - original draft. Junjie Ruan: Writing - original draft. Jinghua Su: Writing - review \& editing.

\section{Declaration of Competing Interest}

The authors declare that they have no known competing financial interests or personal relationships that could have appeared to influence the work reported in this paper. 


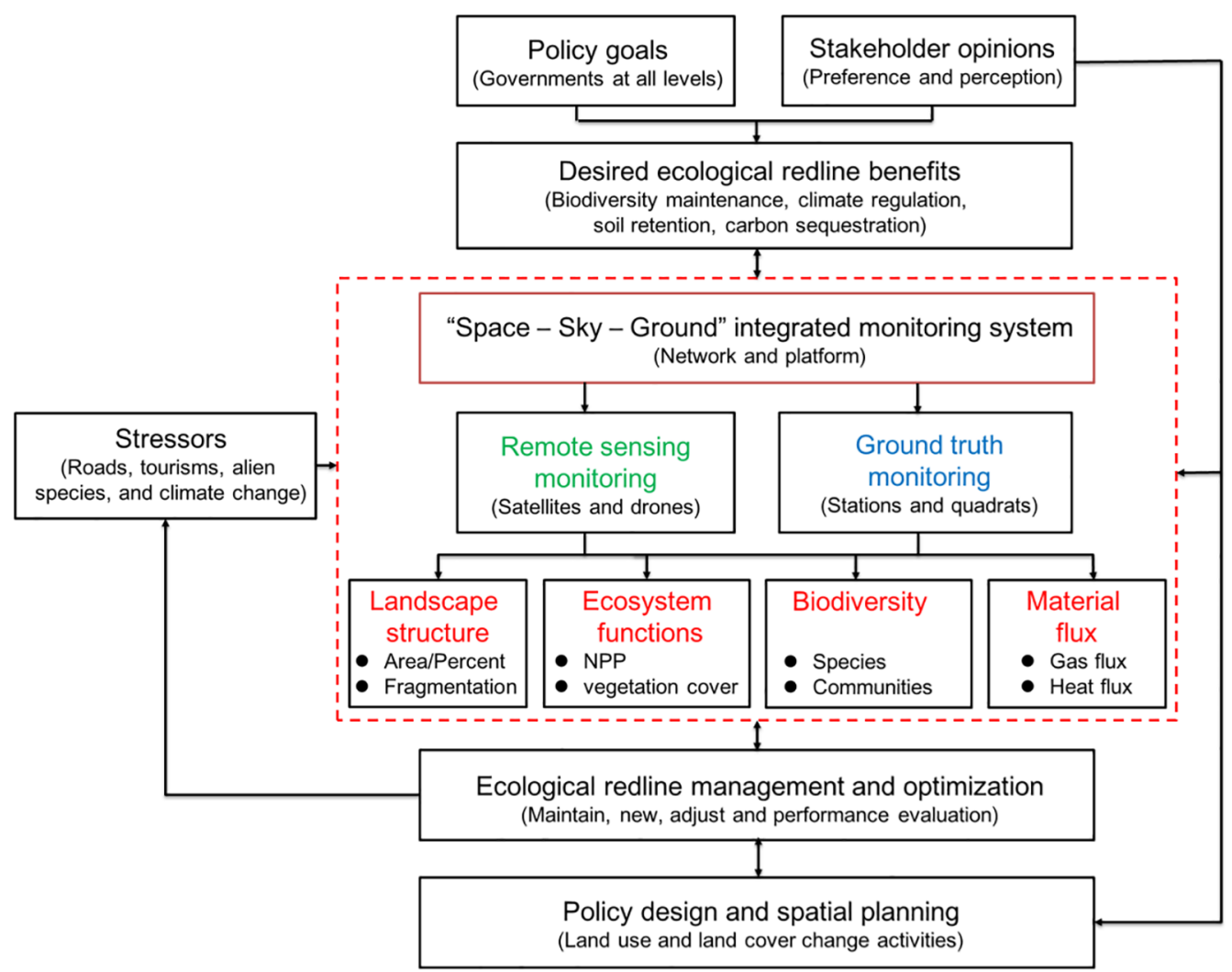

Fig. 1. Standard ecological monitoring (EM) framework for evaluation of Ecological Redline Policy (ERP) measures.

\section{Acknowledgements}

This study was supported by Key Research Program of Frontier Sciences (Grant No. ZDBS-LY-7011), West Light Talent Program of the Chinese Academy of Sciences (Grant No.Y9XB011B01), Science and Technology Commission of Shanghai Municipality, China (Grant No. 18DZ1206500) and Shanghai Municipal Bureau of Ecology and Environment, China (Grant No. 2019-4); JMA was supported by Qatar Petroleum.

\section{Appendix A. Supplementary data}

Supplementary data to this article can be found online at https:// doi.org/10.1016/j.ecolind.2020.106950.

\section{References}

Abella, S.R., Fisichelli, N.A., Schmid, S.M., Embrey, T.M., Cipra, J., 2015. Status and management of non-native plant invasion in three of the largest national parks in the United States. Nature Conservation 10 (91-435), 71-94.

Bai, Y., Jiang, B.o., Wang, M., Li, H., Alatalo, J.M., Huang, S., 2016. New ecological redline policy (ERP) to secure ecosystem services in China. Land Use Policy 55, 348-351.

Bai, Y., Wong, C.P., Jiang, B., Hughes, A.C., Wang, M., Wang, Q., 2018. Developing China's Ecological Redline Policy using ecosystem services assessments for land use planning. Nat. Commun. 9, 3034.

Buckland, S.T., Magurran, A.E., Green, R.E., Fewster, R.M., 2005. Monitoring change in biodiversity through composite indices. Philosophical Transactions of the Royal Society of London. Series B, Biological sciences 360, 243-254.

CMEP, 2014. Technology guide for ecological red line (temporary). (In Chinese) (No. 2014.1). Chinese ministry of Environmental Protection.

CMEP, 2015. Technology guide for ecological red line. (In Chinese). (No. 2015.5).Chinese Ministry of Environmental Protection.

de Groot, R.S., Alkemade, R., Braat, L., Hein, L., Willemen, L., 2010. Challenges in integrating the concept of ecosystem services and values in landscape planning, management and decision making. Ecol. Complex. 7, 260-272.

Fan, X.S., Gao, J.X., He, P., Peng, C.Y., Xu, J., et al., 2018. Technical solutions for ecological red-line management based on problems of ecological security. China Environ. Sci. 38 (12), 4749-4754.

Jiang, B., Bai, Y., Wong, C.P., Xu, X.B., Alatalo, J.M., 2019. China's ecological civilization program-Implementing ecological redline policy. Land Use Policy 81, 111-114.

Kavaliauskas, P., Nurijeva, G., 2015. National parks of United Kingdom, France and Germany: comparative analysis. Geologija. Geografija 1, 130-144.

Li, S.G., Yu, G.R., Yu, X.B., He, H.L., Guo, X.B., 2015. A brief introduction to chinese ecosystem research network (cern). J. Resour. Ecol. 6 (3), 192-196.

Longman, R., Giambelluca, T., Nullet, M., et al., 2018. Compilation of climate data from heterogeneous networks across the Hawaiian Islands. Sci. Data 5, 180012.

Manley, P.N., Schlesinger, M.D., Roth, J.K., Horne, B.V., 2005. A field-based evaluation of a presence-absence protocol for monitoring ecoregional-scale biodiversity. J. Wildl. Manage. 69 (3), 950-966.

Nielsen, S.E., Haughland, D.L., Bayne, E., Schieck, J., 2009. Capacity of large-scale, longterm biodiversity monitoring programmes to detect trends in species prevalence. Biodivers Conserv 18 (11), 2961-2978.

Park, Y.S., Hwang, S.J., 2016. Ecological Monitoring, Assessment, and Management in Freshwater Systems. Water 8, 324.

Peng, Y. 2018. China to build platform for supervising environmental "red lines". Xinhua. 2018-02-18.

Haase, D., Larondelle, N., Andersson, E., Artmann, M., Borgström, S., Breuste, J., GomezBaggethun, E., Gren, Å., Hamstead, Z., Hansen, R., Kabisch, N., Kremer, P., Langemeyer, J., Rall, E.L., McPhearson, T., Pauleit, S., Qureshi, S., Schwarz, N., Voigt, A., Wurster, D., Elmqvist, T., 2014. A Quantitative Review of Urban Ecosystem Service Assessments: Concepts, Models, and Implementation. Ambio 43 (4), 413-433.

Shelford, V. 1941. List of Reserves May Serve as Nature Sanctuaries of National and International Importance, in Canada, the United States, and Mexico. Ecology, 22(1), 100-110.

Xu, D., Zou, C., Xu, M., You, G., Wu, D., 2015. Ecological security pattern construction based on ecological protection redlines. Biodiversity Science 23 (6), 740-746.

Shanghai Municipal People's Government (SMPG). 2018. Ecological protection redline in Shanghai Municipal. 2018-06.

Shoyama, K., Kamiyama, C., Morimoto, J., Ooba, M., Okuro, T., 2017. A review of modeling approaches for ecosystem services assessment in the asian region. Ecosyst. Serv. 26, 316-328.

The State Council, The People's Republic of China. 2017. China to complete drawing ecological 'red line' by 2020. Xinhua, 2017-02-07.

United Nations Environment Programme, 2016. Green Is Gold: the Strategy and Actions of China's Ecological Civilization. UNEP Report, Nairobi.

Yao, L., Ding, Q.L., Yu, Z.N., Lv, T.G., 2019. Review on the research of ecological red-line and systematic framework construction. China Land Science 33 (7), 13-18. 